\title{
Automatisering van de accountantsarbeid
}

'Een organisatieprobleem'

\author{
Drs. A. Eijkenaar
}

\section{Inleiding}

Accountantsarbeid omvat een scala van soorten werkzaamheden: de directe controlewerkzaamheden, de rapportering daarover, de hiervan afgeleide advieswerkzaamheden en de voor de betreffende organisatie benodigde ondersteunende werkzaamheden. In dit artikel wordt geabstraheerd van dienstverlenende activiteiten als het voeren van administraties.

De meeste accountantsorganisaties hebben een eerste automatiseringsronde achter de rug. Men ondervindt nu een aantal knelpunten in de automatisering en men is geneigd zich op deze knelpunten te concentreren. Het is echter van groot belang dat de organisatie zich eerst oriënteert op andere aspecten zoals positie in de branche en eigen specifieke organisatiekenmerken. Vanuit een dergelijke oriëntatie kan de accountantsorganisatie komen tot een automatiseringsplan voor de komende jaren.

\section{Waarom automatisering?}

De twee belangrijkste redenen waarom een accountantsorganisatie over gaat tot automatisering van haar arbeid zijn: handhaving van de kwaliteit en verbetering van de efficiëntie. Daarnaast heeft de automatisering ook neveneffecten als het verhogen van het imago. Wie kent niet de personeelswervingsadvertenties van accountantsmaatschappen waar de personal computer prominent aanwezig is.

De verbetering van de efficiëntie is gericht op het verrichten van accountantswerkzaamheden met zo min mogelijk manuren. Met andere woorden: getracht zal worden werkzaamheden met een repeterend karakter en met relatief veel tijdsbeslag te automatiseren.

De handhaving van de kwaliteit komt onder andere tot uiting in het gebruik van de computer bij complexe berekeningen, dossiervorming en controle in hoog geautomatiseerde omgevingen.

\section{Stand van zaken}

Voor dit artikel wil ik de automatisering binnen de accountantsorganisatie indelen naar beroepssystemen die het controleproces ondersteunen en bedrijfsvoeringssystemen.

De belangrijkste algemene beroepssystemen zijn audit software, tekstverwerking, kolommenbalanssoftware en spreadsheetprogrammatuur. Daarnaast kennen accountantsorganisaties eigen specifieke systemen, zoals handboeken op CD-ROM, expertsystemen ter ondersteuning van de professionalist enzovoort. Dit soort systemen is echter nog geen gemeengoed in accountantsland.

De audit software wordt gebruikt voor het benaderen van, veelal omvangrijke, elektronische bestanden teneinde op de inhoud van deze bestanden selecties, controles en analyses van diverse aard uit te voeren. Vroeger was men voor de toepassing van audit software aangewezen op de computers van de te controleren organisatie. Nu heeft de accountant ook vele mogelijkheden met eigen computers, bijvoorbeeld zijn of haar persoonlijke computer (PC).

Drs. A. Eijkenaar, registeraccountant, studeerde aan de Erasmus Universiteit te Rotterdam. Hij is vennoot van de maatschap Coopers \& Lybrand Dijker Van Dien en voorzitter van de sectie EDP-auditing van het Nederlands Genootschap Informatica. 
De tekstverwerking is met de komst van speciaal daartoe ontwikkelde tekstverwerkers geautomatiseerd. Daarmee werd het arbeidsintensieve corrigeren en soms opnieuw typen verleden tijd. Tegelijkertijd moest men echter constateren dat dit niet leidde tot minder typistes.

Een typiste kon wel effectiever en efficiënter werken, maar kreeg tegelijkertijd meer typewerk aangeboden. Met de komst van de PC op de werkplek is de tekstverwerkingsfunctie in principe bij de professional terecht gekomen. Het controleteam heeft nu de mogelijkheid zelf de teksten in concept aan te leveren. De verbijzonderde typefunctie verzorgt de editing, archivering en verzending. Hiervoor zijn geen afzonderlijke typekamers meer nodig, de typefunctie kan worden uitgevoerd door afdelings- of groepssecretariaten.

Tenslotte kan worden opgemerkt dat op het terrein van de tekstverwerkingspakketten het einde nog niet in het zicht is. In dit verband wil ik noemen de snelle ontwikkelingen in de desk-top publishing pakketten. Hoewel ontstaan als logisch vervolg op tekstverwerking gaat desk-top publishing een geheel eigen plaats innemen in de kantoororganisatie.

De kolommenbalanssoftware is een voorbeeld van automatisering van één specifiek deel van de accountantsarbeid, te weten de verwerking van de kolommenbalans tot een jaarrekening en het uitvoeren van cijferanalyses op deze jaarrekening.

Spreadsheet-pakketten hebben het gebruik van de PC in de accountantsorganisatie een belangrijke stimulans gegeven. Veel rekenwerk, inherent aan accountantscontrole, kan effectief en efficiënt met behulp van een spreadsheetpakket worden uitgevoerd. In tegenstelling tot de tekstverwerking kunnen we stellen dat er in het hulpmiddel spreadsheet weinig ontwikkeling meer mag worden verwacht.

Als bedrijfsvoeringssystemen kunnen worden genoemd: projectensysteem met daaraan gekoppeld de facturering, de personeelsregistratie en -informatiesystemen, salarissysteem, commercieel informatiesysteem en de financiële administratie met daarin geïntegreerd de debiteuren-en crediteurenadministratie.
Een projectensysteem is opgebouwd uit meerdere onderdelen: voorcalculatie, planning, uitvoering, nacalculatie en facturering. In de praktijk zijn de onderdelen voorcalculatie en planning veelal niet of weinig ontwikkeld. Ten aanzien van de overige bedrijfsvoeringssystemen kan worden gesteld dat de meeste accountantsorganisaties op dit punt de nodige automatisering hebben gerealiseerd.

\section{Knelpunten}

De stand van zaken overziend, kunnen we de volgende knelpunten onderkennen: integratie, fysiek beheer, logisch beheer en mens-machine interface.

\section{Integratie}

$\mathrm{Er}$ is nog nauwelijks sprake van integratie tussen de diverse systemen. Personeelsinformatie wordt op meerdere plekken in de organisatie gebruikt en dus onderhouden. De diverse pakketten op de PC kunnen weliswaar fysiek elkaars bestanden lezen, maar er is nog nauwelijks sprake van een logische en efficiënte integratie. De eerste pogingen tot integratie zijn zichtbaar in de zogenaamde 'paraplu-programmatuur'. De diverse pakketten op de PC worden daarbij tot een voor de gebruiker logische eenheid aan elkaar gekoppeld. Van koppeling tussen de bedrijfsvoeringssystemen en beroepssystemen is nog nauwelijks sprake.

\section{Fysiek beheer}

Voor een optimaal gebruik van de PC is uiteindelijk een verhouding werknemer/PC nodig van $1 \mathrm{op}$ 1. Met andere woorden: de PC als echte persoonlijke computer. Deze situatie is in sommige organisaties reeds bereikt c.q. zal op afzienbare termijn worden bereikt. Dit roept het probleem op van het fysiek beheer van de vele, in grote accountantsorganisaties duizenden, PC's.

\section{Logisch beheer}

Met de toenemende automatisering zal het beheer van de cliëntgegevens extra aandacht vragen. De traditionele dossiervorming wordt meer en meer vervangen door bestanden op elektronische gegevensdragers als diskettes, tapes 


\section{MAB}

en vaste schijven in PC's. Op dit moment wordt het probleem opgelost door alle relevante cliëntgegevens volledig af te drukken en volgens de geldende dossiersystematiek op te bergen. Het zal duidelijk zijn dat deze werkwijze niet leidt tot een echte verbetering in de efficiëntie. Daarnaast zien we PC-netwerken ontstaan waarbij de gegevens centraal op vaste schijven staan. Daarmee wordt de problematiek van het logisch beheer en toegang tot deze bestanden alleen nog benadrukt. Het klassieke middel van oogtoezicht werkt hier onvoldoende. De toegangsbeveiliging dient dusdanig te zijn dat ook de vertrouwelijkheid van de cliëntgegevens is gewaarborgd.

\section{Mens-machine interface}

De communicatie tussen mens en machine geschiedt nog steeds via toetsenbord, eventueel aangevuld met een muis en beeldscherm. Dit is geen toonbeeld van efficiëntie. Veel onderzoek wordt op dit moment gedaan naar het inschakelen van de menselijke stem in het interfaceproces. De verwachting is dat het nog vele jaren zal duren alvorens men een betrouwbaar en universeel werkend systeem zal hebben ontwikkeld.

\section{De techniek van de automatisering}

Een belangrijke factor in de ontwikkeling van de automatisering is de voortschrijdende automatiseringstechniek. Voor accountantsorganisaties relevante ontwikkelingen daarin zijn:

- De voortschrijdende verbetering in de prijs/ prestatieverhouding van PC's. Dit betekent dat de persoonlijke computer voor elke professionalist een realiteit wordt met op deze computer een veelheid aan programmatuur.

- De vergevorderde standaardisatie van 'electronic data interchange' en de wereldwijde beschikbaarheid van technisch betrouwbare communicatienetwerken (via satellieten enzovoort), zodat het overzenden van elektronische bestanden tussen computers van accountantsorganisaties en hun cliënten geen problemen meer hoeft te geven.

- De mogelijkheden van optische technieken voor de opslag van grote hoeveelheden gegevens tegen een betaalbare prijs en met de mogelijkheid tot het direct benaderen van deze gegevens via de PC van de professionalist. Het al eerder genoemde voorbeeld van handboeken op CD-ROM is hiervan een direct uitvloeisel.

- De ontwikkelingen op het terrein van expertsystemen. Speciale programmatuur is beschikbaar om de kennis en ervaring van experts, in ons geval accountants, te vertalen naar programmatuur. Daarmee kan de specifieke kennis over bijvoorbeeld het onderkennen van sterke en zwakke punten in een organisatie ter beschikking worden gesteld aan een brede groep van gebruikers mits deze maar de beschikking hebben over een computer, bijvoorbeeld een PC.

\section{Veranderingsprocessen}

Gezien het hiervoor geschetste, zal een accountantsorganisatie geneigd zijn gericht te gaan werken aan het oplossen van de knelpunten, daarbij zoveel mogelijk gebruik makend van de mogelijkheden van de techniek. Het is echter de vraag of dat wel verstandig is. Men zal komen tot deeloplossingen die vervolgens zullen leiden tot een veranderingsproces in de organisatie. Het gevaar bestaat dat de organisatie wordt overvoerd met veranderingsprocessen, de één ingrijpender dan de ander. Nu in de meeste organisaties de automatisering tot een zekere volwassenheid is gekomen en daarmee door de gehele organisatie heen is verweven, zal men naar mijn mening voorzichtig moeten zijn met het doorvoeren van dergelijke veranderingen. Elke verandering vraagt een inspanning die meer dan proportioneel groeit met de omvang van de organisatie.

Met name de grote accountantskantoren met op nationaal niveau duizenden professionals en op internationaal niveau vele tienduizenden zullen dit veranderingsproces met de nodige zorgvuldigheid en ook vindingrijkheid dienen uit te voeren. Naar mijn mening is er daarom een structurele benadering van de hiervoor geschetste knelpunten en ontwikkelingen nodig, teneinde het aantal veranderingen voor de organisatie te minimaliseren. 


\section{MAB}

\section{Information Systems Assessment}

Als hulpmiddel om te komen tot een dergelijke structurele benadering zou ik willen voorstellen te gebruiken een methodiek van Prof. Gordon B. Davis voor 'in-context information systems assessment'. De centrale gedachte hierbij is dat automatisering alleen maar succesvol kan geschieden indien wordt gekeken naar de organisatie en haar eigen unieke karakteristieken. In dit verband worden door Davis drie belangrijke factoren genoemd, te weten:

a De branche waarin de organisatie zich bevindt en de relatieve concurrentiepositie van de betreffende organisatie daarin. Het accountantskantoor dient zich te realiseren dat het een dienstverlenende organisatie is met als belangrijkste actiefposten de human resources en de client-base. Daarnaast zijn zaken van belang als de omvang, de kwaliteit van de dienstverlening en de prijs waartegen de diensten worden verleend in relatie tot die van de concurrent.

b De geschiedenis, cultuur en organisatievorm van de organisatie. De ontstaansgeschiedenis is bijvoorbeeld van belang indien de organisatie in het recente verleden ontstaan is uit een aantal fusies met de daarbij behorende integratieproblematiek. De cultuur kan gericht zijn op informele communicatielijnen, terwijl de automatisering om vooraf gedefinieerde communicatielijnen vraagt. Tenslotte is ook de organisatievorm, centraal geleid met strakke richtlijnen versus decentrale leiding binnen vaste kaders, bepalend voor de keuze van de verdere automatisering.

c De formulering van de informatiebehoefte. In artikelen over automatisering wordt dit aspect vaak genoemd als de meest bepalende voor succes. Uiteraard is een goede informatieanalyse een belangrijke voorwaarde, maar de hiervoor genoemde andere twee aspecten van omgeving en unieke karakteristieken zijn naar mijn mening wel zo belangrijk. De informatieanalyse dient te worden uitgevoerd binnen de begrenzingen van omgeving en organisatie.

In het NIvRA-studierapport 25 'Accountantsar- beid en automatisering' is een uitvoerige informatie-analyse opgenomen van de accountantswerkzaamheden van een 'gestandaardiseerde' accountantsorganisatie. Deze analyse kan als basis dienen voor de eigen informatieanalyse.

\section{Automatiseringsplan}

Kijken we naar de toekomst van de automatisering in een accountantsorganisatie dan zal de organisatie een automatiseringsplan dienen op te stellen met een horizon van minimaal 5 jaar. Liefst zal men deze horizon nog verder in de toekomst willen leggen. Daar alle ontwikkelingen binnen de automatisering over een langere termijn niet kunnen worden voorzien, lijkt 5 jaar echter een redelijk compromis. Tegelijkertijd zal er gestreefd moeten worden naar een zekere flexibiliteit in het automatiseringsplan, teneinde tussentijds bij te kunnen stellen. Bij het opstellen van het automatiseringsplan kan de organisatie zich in de eerste instantie laten leiden door de drie assessmentaspecten van Davis. Dit zal een aantal mogelijke alternatieven geven. Vervolgens zal men zich dienen af te vragen in welke mate daarmee de hiervoor geschetste knelpunten worden opgelost. Tenslotte dient een en ander te leiden tot een automatiseringsplan, zodat de veranderingen voor de organisatie op een gestructureerde en beheerste wijze kunnen verlopen.

\section{Overwegingen voor de toekomst}

Welke overwegingen kunnen een rol spelen bij de 'information systems assessment' van een accountantsorganisatie?

\section{Voorsprong ten opzichte van de concurrent}

Grote organisaties kunnen daarbij gebruik maken van hun omvang die hen in staat stelt eigen unieke beroepssystemen te ontwikkelen. Voorbeelden hiervan zijn: expertsystemen gericht op de analyse van de cliëntenorganisatie en in aansluiting daarop het vervaardigen van 'op maat gesneden' werkprogramma's of het wereldwijd verspreiden van controlelijnen via CD-ROM. 


\section{MAB}

Bundeling automatiseringskennis en -ervaring Een grote organisatie is eerder in staat een kleine groep van hoogwaardige automatiseringsspecialisten bijeen te brengen, teneinde de technische ontwikkelingen in de automatisering te vertalen naar strategische toepassingen. Middelgrote organisaties zullen genoodzaakt worden op dit punt samen te werken, daar de grotere organisaties niet snel geneigd zullen zijn deze 'kennis' te delen. Men ziet het met recht als strategisch. De internationale confrontatie 'automating the audit' gehouden in november 1989 te Brussel, was daarvan een voorbeeld. Er waren vele sprekers maar niemand sprak over hun systemen in ontwikkeling. Men ging uitsluitend in op reeds operationele toepassingen voor accountantsorganisaties.

\section{Omvang van de organisatie}

De grote internationale organisatie zal veel energie moeten steken in het formuleren van wereldwijde, de gehele organisatie omspannende, eisenspecificaties waarna de betreffende systemen gebouwd kunnen worden, al dan niet in eigen beheer. Daarnaast dient men in dergelijke situaties de invoeringsproblematiek niet te onderschatten. Men dient daarbij te denken aan minimumeisen te stellen aan apparatuur en automatiseringskennis. De invoering van een nieuw systeem zal moeten worden gedaan met behulp van een adequaat trainingsprogramma. De middelgrote en kleine organisaties hebben op dit punt een voordeel ten opzichte van de grote organisaties.

\section{Standaardpakketten}

Accountantsorganisaties zijn inmiddels vele jaren bezig met automatisering. Men ziet dat er specifiek voor accountantsorganisaties ontwikkelde programmatuur beschikbaar komt op de markt. Hoewel niet het meest geavanceerd maar wel bewezen in de praktijk, kan dit een goed alternatief zijn. Wat let ook een grote organisatie om pakketten aan te kopen? De werking is bewezen en men kan zich concentreren op de invoering.

\section{Betrokkenheid van het management}

Sommige accountantsorganisaties kennen een managementstijl waarbij centrale sturing van de organisatie wordt beperkt tot zaken van strategische aard. Automatisering zal in een dergelijke situatie ook daartoe dienen te worden gerekend. Voor accountantsorganisaties zal automatisering in de komende jaren een strategisch item zijn dat om een centrale aansturing vraagt. Betrokkenheid van het topmanagement is een vereiste, gezien de omvang van de benodigde investeringen in opleidingen, computers, systeemontwikkeling en de voortdurende noodzaak tot verhoging van de efficiëntie.

\section{Formulering eisen en wensen}

Het uiteindelijk formuleren van eisen en wensen is een vrij moeizaam proces, zoals elke organisatie die wil automatiseren kan ervaren. Hiervoor is reeds geschetst waar een grote wereldwijd opererende accountantsorganisatie voor komt te staan. Meestal mondt dit proces uit in een compromis waarin de meesten zich kunnen vinden. Met name zullen er problemen ontstaan bij toepassingen die op enigerlei wijze de uitvoering van de controle moeten gaan ondersteunen. Wereldwijd kennen we immers verschillen veroorzaakt door cultuur, bedrijfseconomische opvattingen (waarderingsgrondslagen, inrichting jaarrekening), controletechnische opvattingen, enzovoorts. Alleen centraal geleide organisaties kunnen met dit soort toepassingen goed overweg. Men zal het willen gebruiken om de controle-uitvoering wereldwijd nog meer te standaardiseren dan men al gewoon is.

\section{Opheffen knelpunten}

Als belangrijkste knelpunten in de huidige toepassingen zijn genoemd de integratie, het fysiek beheer, het logisch beheer en de mens-machine interface. Op dit moment concentreren de meeste accountantsorganisaties zich op één of meer van deze knelpunten uitgaande van bestaande toepassingen. Gezien de inmiddels vrij hoge penetratiegraad van PC's en de daarin verwachte ontwikkeling naar een ratio van één $P C$ per professional, wordt nu gewerkt aan software welke zowel het probleem van de integratie van de diverse toepassingen als het probleem van het logische beheer kan oplossen. 


\section{MAB}

Voorlopig beperkt men zich daarbij tot de beroepssystemen. De oplossing wordt gezocht in PC-programmatuur die enerzijds de toegang tot op de PC aanwezige toepassingen en bestanden bewaakt en anderzijds de integratie mogelijk maakt van deze toepassingen en bestanden. Met andere woorden: de professionalist krijgt na een aanlogprocedure, waarin een autorisatieprocedure is opgenomen, een hoofdmenu met voor alle voor hem beschikbare toepassingen op het scherm. De toepassingen zelf zullen voor een deel bestaan uit bestaande programmatuur waar nodig aangepast op het punt van het bestandsbeheer. Bestanden betreffende één cliënt worden daarbij beheerd vanuit het hoofdprogramma.

\section{Informatie-overdracht via elektronische netwerken}

Is het probleem van het logisch beheer eenmaal adequaat opgelost dan is ook een belangrijke stap gedaan in de richting van het gebruik van netwerken voor het transport van cliëntendossiers c.q. delen daaruit. Technisch is het reeds mogelijk om bestanden snel en foutloos over te zenden naar welke plek ook ter wereld. Of dit nu een andere werkplek binnen het kantoor is of een andere vestiging van de organisatie maakt in principe niets uit. Indien aan de voorwaarde van een goed beheer van de bestanden bij de zendende en ontvangende partij, waarin ook de autorisatie op een adequate wijze is geregeld, is voldaan, rest nog de problematiek van de afscherming van de gegevens tijdens het transport over de netwerken.

Een zorgvuldige afweging van kosten (encryptie van data) en baten (geen aantasting van de vertrouwelijkheid) is in deze gewenst.

\section{Samenvatting}

Accountantsorganisaties staan na een eerste automatiseringsgolf voor de uitdaging de groei in de automatisering binnen hun organisaties te blijven beheersen, de technische ontwikkelingen zo goed mogelijk aan te wenden en tegelijkertijd een verhoging van de huidige efficiëntie te bereiken onder handhaving van de kwaliteit van de dienstverlening. Dit vraagt om investeringen in research, een structurele bemoeienis met automatisering tot op het hoogste niveau van de leiding en een gebruik maken van de unieke eigenschappen van de organisatie.

De tweede automatiseringsgolf zal de accountantsorganisaties in staat moeten stellen ook in de jaren negentig en daarna de werkzaamheden op een efficiënte en effectieve wijze uit te voeren. Deze automatisering zal enerzijds het karakter dragen van integratie en beheersbaar maken en anderzijds een innovatief karakter hebben met geheel nieuwe toepassingen, daartoe in staat gesteld door de technische ontwikkelingen.

\section{Literatuur}

Accountantsarbeid en automatisering: een inventarisatie van mogelijkheden. Studierapport 25, NIvRA.

Bjon-Andersen, N. en G. B. Davis, Information Systems assessment: issues and challenges, 1988.

Bruys, M. Accountantskantoren en Automatisering in $A \& B$, 1989/7.

CICA, Information Technology: Change Response for the CPA Profession, oktober 1989.

Gabriel, R. und W. Knop, Ein Computergestütztes Planungssystem zur Durchführung von Jahresabschlussprüfungen für eine Wirtschaftprüfungsgesellschaft, Schmalenbacks Zeitschrift für betriebswirtschaftliche Forschung, 1988,12.

IT and the future of the audit, The Institute of Chartered Accountants in England and Wales, 1989.

Ruhle, K. Expertensysteme als Prüfungswerkzeuge, Die Wirtschaftsprüfung, maart 1990 